\title{
Evaluation of passive autocatalytic recombiners operation efficiency by means of the lumped parameter approach*
}

\begin{abstract}
The problem of hydrogen behavior in containment buildings of nuclear reactors belongs to thermal-hydraulic area. Taking into account the size of systems under consideration and, first of all, safety issues, such type of analyses cannot be done by means of full-scale experiments. Therefore, mathematical modeling and numerical simulations are widely used for these purposes. A lumped parameter approach based code HEPCAL has been elaborated in the Institute of Thermal Technology of the Silesian University of Technology for simulations of pressurized water reactor containment transient response. The VVER-440/213 and European pressurised water reactor (EPR) reactors containments are the subjects of analysis within the framework of this paper. Simulations have been realized for the loss-of-coolant accident scenarios with emergency core cooling system failure. These scenarios include core overheating and hydrogen generation. Passive autocatalytic recombiners installed for removal of hydrogen has been taken into account. The operational efficiency of the hydrogen removal system has been evaluated by comparing with an actual hydrogen concentration and flammability limit. This limit has been determined for the three-component mixture of air, steam and hydrogen. Some problems related to the lumped parameter approach application have been also identified.
\end{abstract}

Key words: hydrogen $\bullet$ lumped parameter modeling $\bullet$ nuclear reactor $\bullet$ passive autocatalytic recombiners

T. Bury

Institute of Thermal Technology,

Division of Heat Transfer and Nuclear Power

Engineering,

Silesian University of Technology,

22 Konarskiego Str., 44-100 Gliwice, Poland, Tel.: +48 32237 2416, Fax: +48 32237 2872,

E-mail: tomasz.bury@polsl.pl

Received: 12 December 2014

Accepted: 30 March 2015

\section{Introduction}

The problem of uncontrolled hydrogen combustion within containment of nuclear reactors is one of the most important concerns regarding safety of nuclear power engineering. Combustion or explosion of hydrogen may threaten the maintenance of basic safety function in a nuclear reactor, that is, isolation of radioactive material from the environment. The accident in Fukushima Daiichi Power Plant has shown how destructive such an event could be. Even if the containment structure withstood the combustion (as it happened during the Three Mile Island Unit 2 accident), some damages to the equipment may occur. Therefore, it is crucial to identify sources of hydrogen, possible pathways of its release into the reactor building and its behavior in the containment atmosphere.

Gaseous hydrogen is generated in nuclear reactor systems during their normal operation by water radiolysis, but this is a minor source of this gas.

\footnotetext{
* This paper is based on a lecture given at the Polish Energy Mix-2014 Conference held at Ustroń Śląski, Poland, on 15-17 October 2014.
} 
However, in conditions after an accident, much more powerful hydrogen sources may appear. The corrosion of metals in a post-accidental atmosphere is one of them, but it is rather minor source. A bigger source of hydrogen could be a molten core (corium) reaction with concrete - molten corium-concrete interaction. This mechanism of hydrogen generation in the later phase of a severe accident is expected to produce 1-2 kg of hydrogen/s [1]. One of the most important sources of hydrogen is steam and zirconium reaction taking place in the core at elevated temperatures. This source of hydrogen is characteristic for an accident, leading to the core overheating, as a loss-of-forced-coolant circulation or a loss-of-coolant accident (LOCA). The last one of the most dangerous type of accident in water cooled reactors. It is initiated by a break in the primary cooling circuit, followed by rapid coolant leakage. Through the break, hydrogen may leak out of the primary circuit and mix with the air present in the containment building. If hydrogen is distributed uniformly in the containment building of a light water reactor its concentration is insufficient to pose a threat to the containment integrity. However, if this gas is distributed non-uniformly, a risk of detonation can appear. Thus, the important matter is to understand where a high local concentration of hydrogen may occur.

Knowledge about hydrogen behavior within containment is crucial for proper design of the hydrogen removal system. Five methods of hydrogen risk mitigation can be distinguished: pre- or post-accident atmosphere inertization (by injection of an inert gas), atmosphere mixing, deliberate hydrogen ignition, extension of the containment volume and hydrogen removal by active or passive catalytic devices. The last method is a subject of many researches as it is the passive way for hydrogen removal - it does not need any external energy supply. Passive autocatalytic recombiners (PARs) are self-starting devices and utilize noble metal (platinum, palladium) coated surfaces in order to recombine gaseous hydrogen molecules into steam. Efficient hydrogen removal requires proper placement of the hydrogen removal devices.

A catalytic recombiner is passive device - no external energy is needed for its operation, and is self-starting also at low temperatures and wet conditions. The recombiner consists of a vertical channel or stack equipped with a catalyst cartridge in the lower part. Such design creates the so-called chimney effect - a gas mixture flows through the recombiner by means of natural circulation. The operation of a PAR is based on the exothermic reaction of hydrogen and oxygen present in the containment atmosphere taking place on the catalyst surface. The catalytic cartridge contains plates or spheres coated with noble metals: palladium or platinum. The simplified diagram of a PAR is shown in Fig. 1.

It is obvious that thermal-hydraulic analysis of hydrogen behavior within a containment is not possible by means of full-scale physical experiments. Thus, mathematical modeling and numerical simulations are applied for these purposes. Most

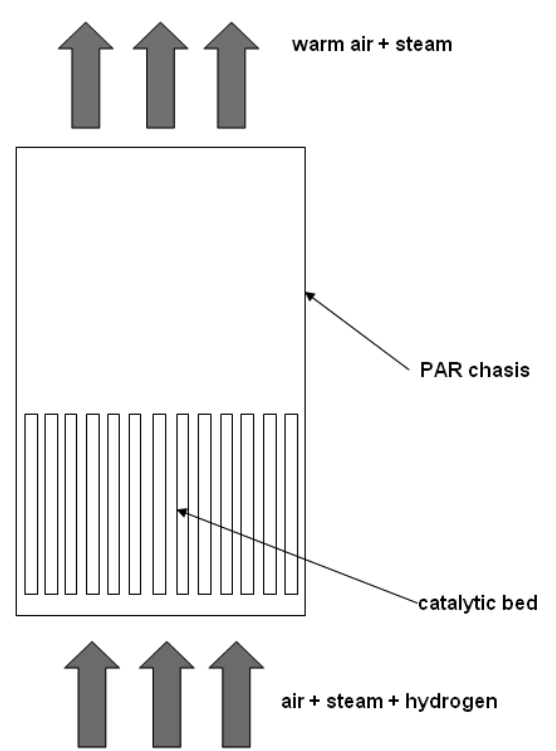

Fig. 1. Simplified diagram of the passive autocatalytic recombiner (PAR).

phenomena taking place within containment of a water-cooled reactor during a LOCA is clearly three-dimensional (natural circulation, mixing, and stratification). Owing to this, computational fluid dynamics (CFD) modeling currently seems to be a natural choice. Unfortunately, the size and complexity of the systems under consideration makes the CFD approach very limited. The lack of appropriate validation is an additional problem. Only small areas of the containment or specific phenomena are analyzed usually. This study concerns a lumped parameter approach.

\section{Characteristic of the lumped parameter numerical model}

The results received here are an affect of simulations performed using the code HEPCAL-AD, worked out at the Institute of Thermal Technology [2]. This code requires a division of the internal space of the accident localization system onto control volumes of specified dimensions, connected to each other in the given way. Usually, the geometry and dimensions of a control volume correspond to the real dimensions of the specified compartment of the accident localization system. The control volumes are connected through opened channels, orifices, valves, membranes or siphon closures. This approach can be called some kind of the finite volume method, applied in most of CFD codes. However, the size of control volumes is much bigger than in any CFD model and the resolution of results is low - average values of thermodynamic and hydraulic parameters are calculated.

The mathematical basics of the model describing changes of thermodynamic parameters present equations of mass and energy balance for specified phases and equations of state. The equations of mass and energy balance apply to the time step $\Delta \tau$; however, the equations of state concern to the end of 
each time step $[2,3]$. All the equations are nonlinear and their form depends on the state of the specified agents in the control volume. The basic equations of the model may be written in following form:

- equation of the energy balance for the gaseous phase

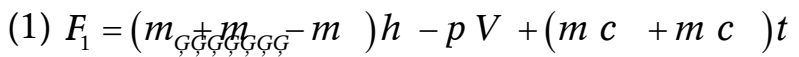
$+m_{s c} h_{s}{ }^{\prime}\left(t_{g}\right)-m_{w e} h_{s}{ }^{\prime \prime}\left(t_{w}\right)-U_{g 1}-\Delta E_{g}=0$

- equation of the energy balance for the liquid phase

(2)

$$
F_{2}=\delta_{1}\left[\begin{array}{l}
\left(m_{w}-m_{w e}+m_{s c}\right) c_{w w} t_{w}-m_{s c} h_{s}{ }^{\prime}\left(t_{g}\right) \\
+m_{w e} h_{s}{ }^{\prime \prime}\left(t_{w}\right)-U_{w 1}-\Delta E_{w}
\end{array}\right]=0
$$

- equation expressing the sum of the agents volumes

$$
\begin{aligned}
F_{3} & =\left(m_{s}+m_{w e}-m_{s c}\right) v_{s} \\
& +\left(m_{w}-m_{w e}+m_{s c}\right) v_{w}-V_{t o t}=0
\end{aligned}
$$

- equation expressing the sum of the partial pressures

$$
F_{4}=\delta_{2}\left[p_{a}+p_{h}+p_{s}\left(t_{g}\right)-p_{s}\left(t_{w}\right)\right]=0
$$

where: $h$ - specific enthalpy; $h, h "$ - refer to saturated water and steam, respectively; $c$ - specific heat capacity; $v, V$-specific and total volume; $m_{w e}$ - mass of water being evaporated during the time step $\Delta \tau$; $m_{s c}$ - mass of steam being condensed during the time step $\Delta \tau ; U_{g 1}, U_{w 1}$ - internal energy of gas and water at the beginning of time step; $\Delta E_{g}, \Delta E_{w}$ - sum of energy flow rate flowing into the control volume (enthalpy of gas and water and heat fluxes).

Subscripts $a, s, h, g$ and $w$ refer to air, steam, hydrogen, gas (mixture of air, steam, and hydrogen) and water, respectively. Constants $\delta_{1}$ and $\delta_{2}$ amount to 0 or 1 , depending of the state of steam and water in specified control volume.

The calculations of the unknown quantities are realized in several steps. First, all the mass and energy fluxes are calculated (the leakage of coolant from the primary circuit, the flow rates of agents through the valves, orifices, water flow rate in the spraying system, and heat accumulation in walls and structures). Heat transfer between gaseous and liquid phase is also determined. All these calculations refer to the thermal parameters at the beginning of time step and allow calculating the internal energy of gas and liquid. Eventually, one obtains a set of $n$ nonlinear equations in the following general form:

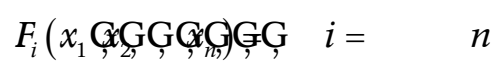

where $x_{i}$ denotes an unknown parameter. The number of equations depends on the current state of agents within the control volume.

The set of nonlinear equations is solved using the Newton-Raphson method. The required accuracy is provided by applying the iterative procedure. At the last step of calculations, all the remaining quantities (partial pressures, total volumes of gas, and water etc.) are calculated. The computational procedure is repeated in the each time step for each control volume.

The model applied in the HEPCAL code allows determining the thermal parameters in the specified volumes (temperature, pressure, and density) and the mass and energy flow rates between the control zones. The spraying system work is taken into account, and also heat transfer between phases and heat accumulation in the structures of the containment.

It should be noted here that the HEPCAL code does not simulate processes taking place inside the primary circuit and therefore additional information is necessary to provide data concerning the coolant leak into the containment (its mass flow rate and specific enthalpy). These data are the initial and boundary conditions for the HEPCAL simulations and are taken from external sources (experiments or other codes simulations).

\section{Model of the passive autocatalytic recombiner}

The PAR is a self-activated device - the recombination of hydrogen starts just after its concentration in an inflowing gas mixture crosses the given limit (1-2\% by volume usually). The model of hydrogen removal system needs definition of additional terms in the mass and energy balance equations described earlier. The recombination reaction product is steam, which should be taken into account in the mass balance for gaseous phase, as well as in the energy balance. The reaction under consideration is an exothermic one and heat of this reaction is also considered in the energy balance. It is impossible to model the actual position of a PAR in a control volume in the lumped parameter approach. Therefore, for the specific control zone, a total recombination rate is considered.

The recombination rate is given for nominal parameters (temperature, pressure, and hydrogen concentration), but during an accident course these parameters vary. A part of these parameters has a negligible impact on the recombination rate, but others are important. In Fig. 2, there is presented the hydrogen concentration impact on the relative recombination rate (the actual one to the nominal).

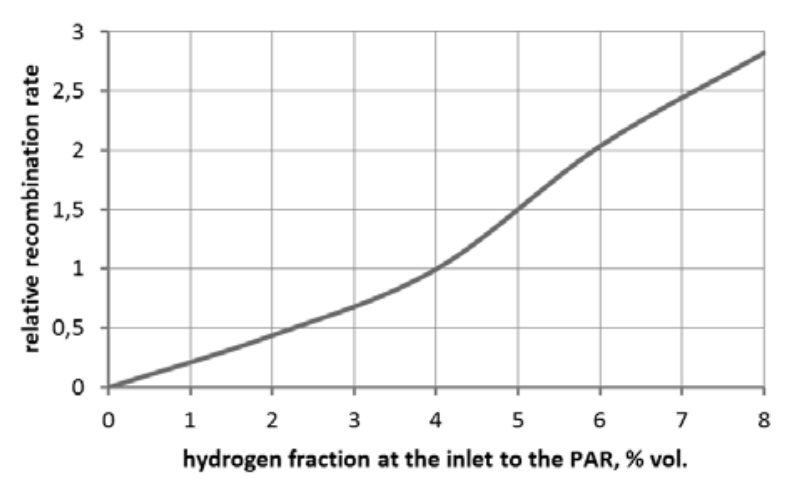

Fig. 2. Influence of the hydrogen fraction at the inlet to a PAR on the recombination rate. 
The PAR's characteristic shown in Fig. 2 has been elaborated according to CFD simulations performed using the PAR model [4].

\section{Analyzed objects and its numerical models}

\section{The VVER-440/2 13 reactor}

Pressurized water reactors of the VVER-440/213 type have a containment building that is connected with a bubble condenser. The bubble condenser acts as a pressure suppression system by condensation of released steam. Specific features of the VVER-440/213 containment are the subdivided rectangular building and the localization tower, including the bubbler trays and air traps (Fig. 3). The containment is designed to prevent the escape of steam and fission products in any LOCA cases, including the double-ended guillotine rupture of a $500 \mathrm{~mm}$ diameter main circulation pipe (this is the design basis accident; [5]). The design pressure of the containment is $0.25 \mathrm{MPa}$.

The accident localization system consists of the bubble condenser and the air traps. The aim of the localization system is to decrease the maximum pressure and ensure the near atmospheric pressure after 5-10 min of the pipe break [6]. The localization tower contains about $1500 \mathrm{~m}^{3}$ of water distributed among 12 elevation of trays. The air volume of trays is connected to four air traps through the check valves. The steam condenses flowing to the water trays through a layer of the water. Non-condensable gases and air accumulate in the gaseous space of the water trays and, after crossing the border pressure, flow to the air traps.

The hydrogen removal system under consideration is equipped with 28 PARs of FR1-1500T type and 4 devices of FR1-750T type manufactured by AREVA. The nominal capacity of these PARs is equal to $160 \mathrm{~kg}$ of hydrogen/h for reference conditions (absolute pressure $150 \mathrm{kPa}$, temperature $60^{\circ} \mathrm{C}$

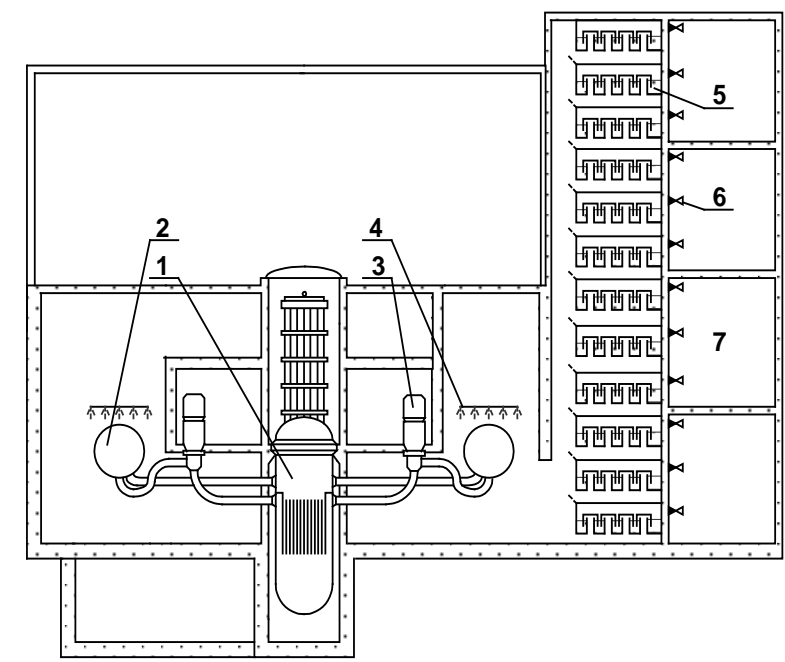

Fig. 3. Simplified sketch of the VVER 440/213 reactor containment ( 1 - reactor pressure vessel, 2 - steam generators, 3 - reactor coolant pumps, 4 - spraying system, 5 - water trays, 6 - check valves, 7 - air traps).

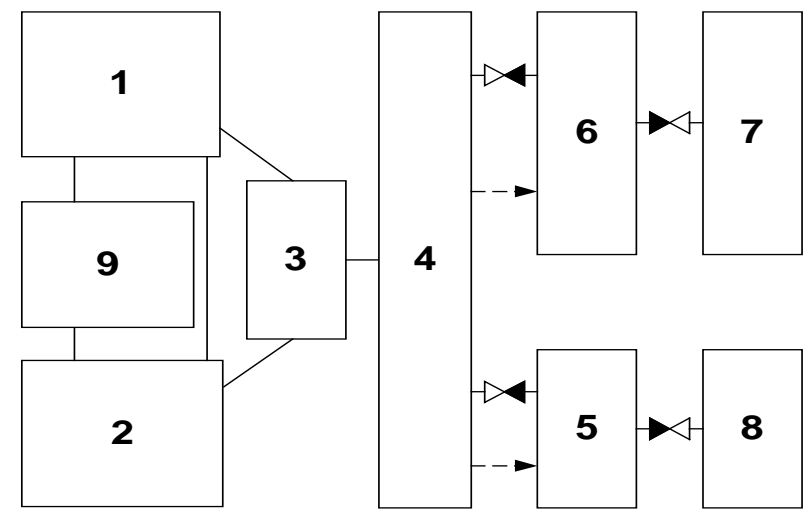

Fig. 4. Nodalization scheme of the VVER-440/213 containment building.

and hydrogen concentration of 4\%). The PARs start their operation at the hydrogen concentration equal to $2 \%$ (volume fraction) [7].

According to the requirements of the applied mathematical model, the containment structure under consideration has been divided on nine control volumes. The nodalization scheme is shown in Fig. 3 and it is as follow: zone 1 - volume of $6370 \mathrm{~m}^{3}$ (half of the steam generator boxes); zone 2 - volume of $6370 \mathrm{~m}^{3}$ (half of the steam generator boxes); zone 3 - volume of $2000 \mathrm{~m}^{3}$ (connecting channel); zone 4 - volume of $3000 \mathrm{~m}^{3}$ (the shaft of the accident localization tower); zone 5 - volume of $2667 \mathrm{~m}^{3}$, including $500 \mathrm{~m}^{3}$ of water (water trays -4 lower levels); zone 6 - volume of $5333 \mathrm{~m}^{3}$, including $1000 \mathrm{~m}^{3}$ of water (water trays - remaining levels); zone 7 - volume of $4200 \mathrm{~m}^{3}$ (first air trap); zone 8 - volume of $12600 \mathrm{~m}^{3}$ (remaining air traps); zone 9 - volume of $6000 \mathrm{~m}^{3}$ (closed subcompartments connected to the steam generator boxes with open channels of constant flow cross-section area).

In Fig. 4, the continuous lines mean junctions by open channels of constant flow cross-section area and dashed lines mean junctions by siphon closures.

\section{The European pressurized water reactor}

The evolutionary EPR is the third-generation reactor, with the thermal output varying from 4300 to $4600 \mathrm{MW}$ (depending on local conditions). This AREVA's design constitutes an evolutionary approach which utilizes proven in practice safety solutions known from the second-generation nuclear power plants [8]. All safety-related systems are designed with a four-fold redundancy and located in physically separate divisions [9].

The inner containment is a pre-stressed concrete cylindrical wall with an elliptical head and a reinforced concrete base mat (as shown in Fig. 5). A metallic liner fitted on the inner surface ensures the leak tightness of the containment. The inner containment shell can withstand a build-up in pressure, occurring even after the double-ended break of the main primary coolant pipe. Exclusion of violent phenomena that can result from the production of hydrogen is provided by passive catalytic recombiners to consume hydrogen. The pressure increase that 


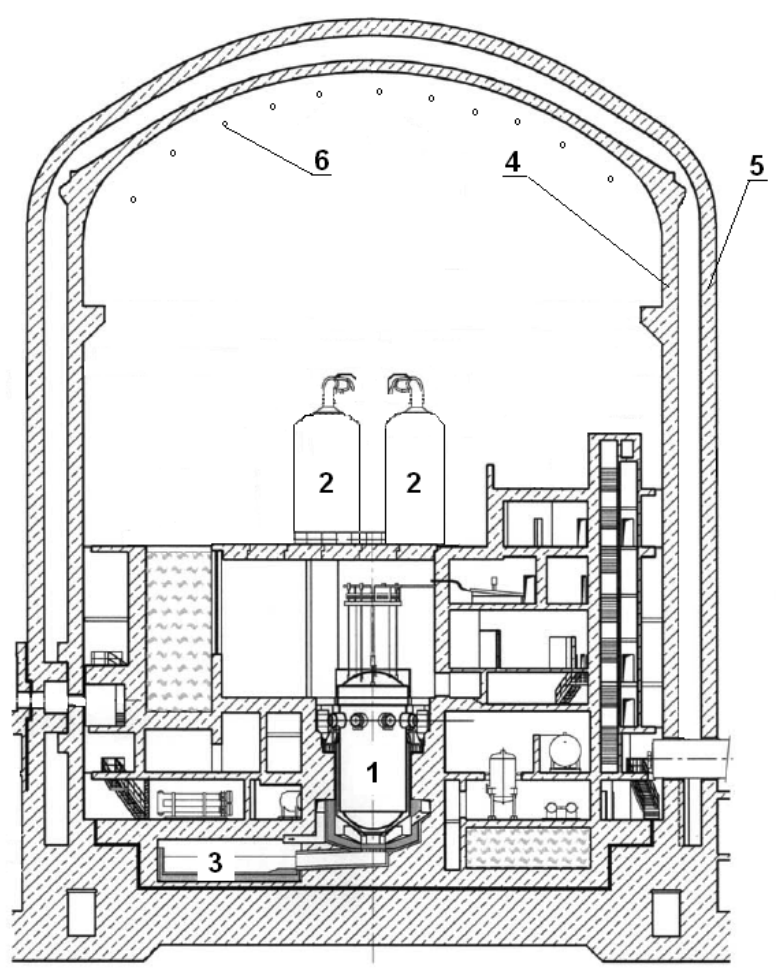

Fig. 5. Simplified cross section of the EPR containment - prepared according to [6]. (1 - reactor pressure vessel, 2 - steam generators, 3 - core catcher, 4 - inner containment, 5 - outer containment, 6 - spraying system nozzles).

would result from the combustion of hydrogen is taken into account in the containment design.

The containment is segregated into two zones, delineating areas that are accessible during normal operation from those that are inaccessible. In the event of an accident, communication is established between these zones by opening mixing dampers and foil barriers, thereby transforming the containment into a single convective volume. This transformation into a single convective volume is performed by the CONVECT system, which equalizes pressure between the containment compartments and promotes efficient mixing of the atmosphere by establishing a global convective pathway [10].

The system under consideration is equipped with 41 PARs of FR1-1500T type and 6 devices of FR1-380T type manufactured by AREVA. The nominal capacity of these PARs is almost $220 \mathrm{~kg}$ of hydrogen $/ \mathrm{h}$ for reference conditions (as stated earlier).

The primary containment of the EPR has the free volume of over $80000 \mathrm{~m}^{3}$. The arrangement of subcompartments and connections between them allow for natural circulation flows, thus promoting efficient mixing of the internal atmosphere contents, as mentioned earlier. The structure of the EPR containment is very complex and consists of nearly 140 subcompartments. It is usual during thermal-hydraulic analyses of such systems to simplify them by treating subcompartments of the containment connected by open channels as one control volume. Thus, in the first approach, the analyzed EPR containment was divided into five control zones: zone 1 (steam generator boxes) - $14775 \mathrm{~m}^{3}$, zone 2 (upper dome) - $42000 \mathrm{~m}^{3}$, zone 3 (reactor pit +

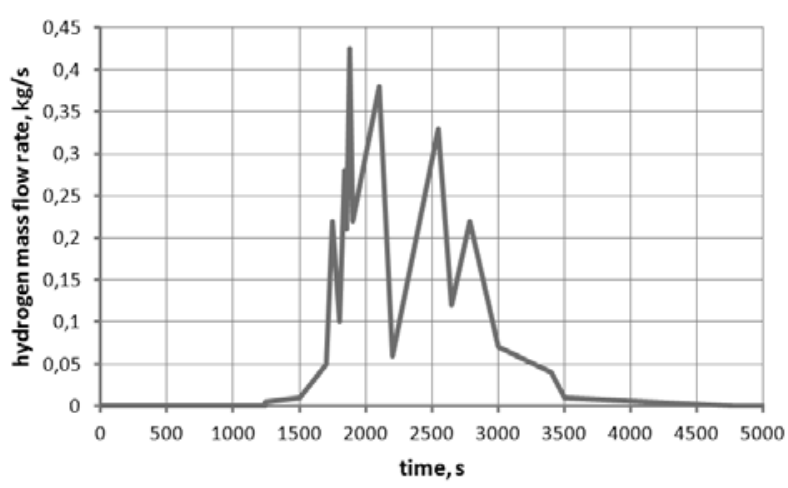

Fig. 6. VVER 440/213 reactor analysis: mass flow rate of hydrogen entering the break zone.

core catcher) - $1460 \mathrm{~m}^{3}$, zone 4 (annular space near the primary containment wall) $-22000 \mathrm{~m}^{3}$, zone 5 (space between primary and secondary containment) - $12260 \mathrm{~m}^{3}$.

\section{Results of simulations}

\section{The VVER-440/2 3 reactor}

The analyzed accident scenario is medium break LOCA. The accident is initiated by a rupture of the primary circuit pipe of effective diameter equal to $100 \mathrm{~mm}$. The break takes place in the steam generator boxes (zone 1). The low and high pressure emergency coolant injection as well as the active spraying system is unavailable during the accident [11]. Hydrogen is produced in steam-zirconium reaction within the core region and is next released into the containment via the break. Figure 6 presents the mass flow rate of hydrogen released into the break zone. It was assumed that the temperature of hydrogen is constant and equal to $500^{\circ} \mathrm{C}$.

The most interesting results are the mass of hydrogen released into the containment and its concentration (fraction by volume). The time-dependent trends of these parameters have been presented in Figs. 7 and 8 . The results concern the control zone number 1 where the rupture of the primary circuit was assumed.

The first stage of simulations has been realized without operation of the hydrogen removal system - continuous lines in Figs. 7 and 8. Taking into account a $4 \%$ flammability limit, it can be seen in Fig. 8 that this limit is achieved within approximately 20 min after first portion of hydrogen appears in the steam generator boxes.

The operation of the PARs-based hydrogen removal system has been simulated in the next step. Computations were accomplished assuming constant capacity of the catalytic devices (dotted lines) as well as the capacity varying according to the characteristics shown in Fig. 2 (dashed lines). As mentioned before, the PARs are activated after crossing the $2 \%$ hydrogen concentration limit. The hydrogen removal system operation allows for recombining over $50 \mathrm{~kg}$ of this gas within the analyzed time period. The hydrogen flammability limit is crossed in this case too (see Fig. 8), but the concentration of hydrogen falls down below this limit 


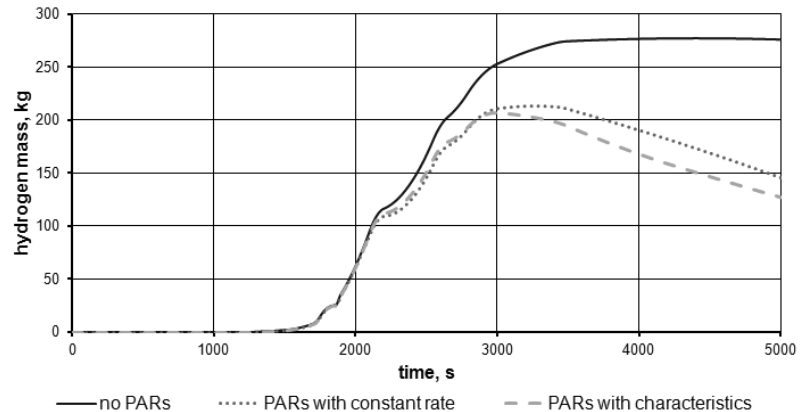

Fig. 7. VVER 440/213 reactor analysis: mass of hydrogen accumulated within the break zone.

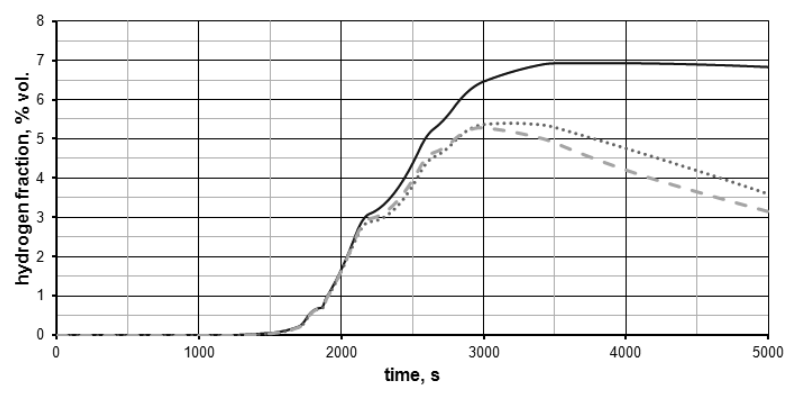

—no PARs ….. PARs with constant rate - - PARs with characteristics

Fig. 8. VVER 440/213 reactor analysis: hydrogen volumetric fraction within the break zone.

within approximately $37 \mathrm{~min}$. Differences in two approaches in PARs operation modeling are visible.

\section{The EPR reactor}

The accident scenario under consideration is a hot leg LOCA of an effective break diameter equal to $100 \mathrm{~mm}$. The pipe rupture occurs in the steam generator boxes. It has been assumed that no emergency cooling systems are available during the accident and the steam-zirconium reaction was the source of gaseous hydrogen in the case.

The mass flow rate of hydrogen entering the break zone (steam generator boxes) is presented in Fig. 9. Figure 10 presents the hydrogen concentration in the break zone and in the upper dome of the containment building. It can be clearly seen that taking into account the dependence of the recombination rate on the amount of hydrogen present in the inlet stream influences the results to a large degree.

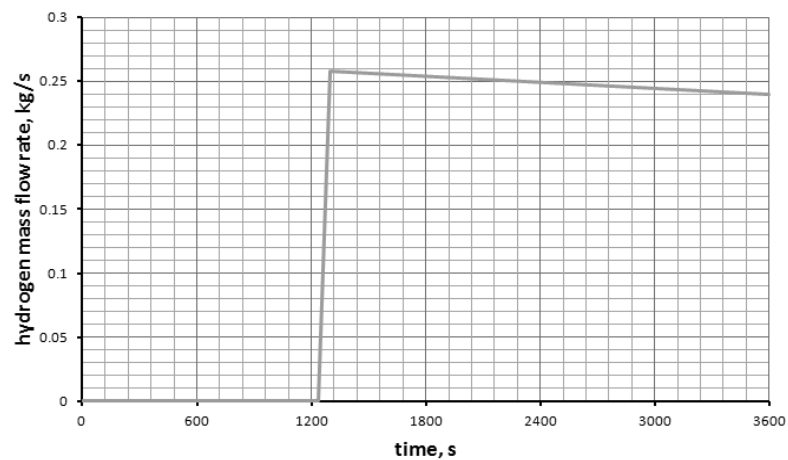

Fig. 9. EPR reactor analysis: mass flow rate of hydrogen entering the break zone.

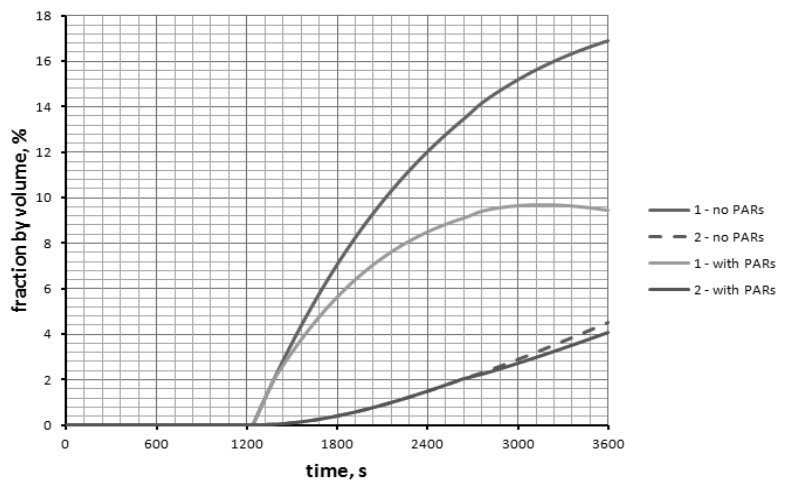

Fig. 10. EPR reactor analysis: hydrogen volumetric fraction within the break zone (1) and under the containment dome (2).

The recombination rate is more efficient while there is more hydrogen in the gaseous mixture flowing into the catalytic devices.

One of the crucial issues in the lumped parameter approach is division of the analyzed object on control volumes (nodalization). The EPR containment building has about 140 rooms which, in the second approach, were lumped in 27 control zones. The nodalization scheme was adopted from [12] and is presented in Fig. 11. The same LOCA scenario as earlier was analyzed, but the break occurs in control zone 4 (lower equipment room). This area is a part

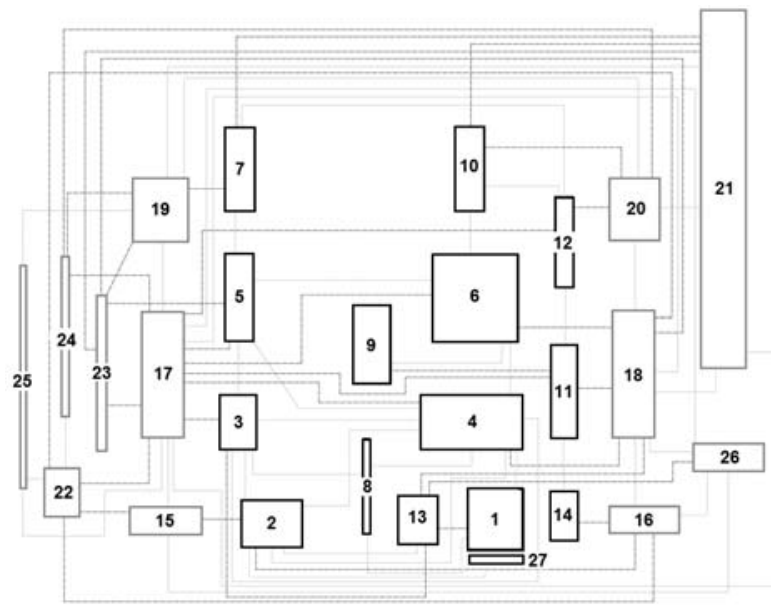

Fig. 11. Nodalization scheme of the EPR containment building.

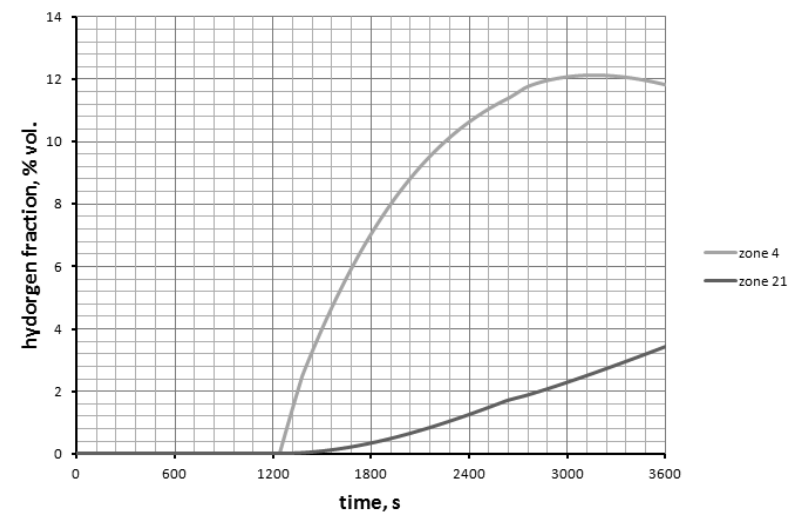

Fig. 12. EPR reactor analysis - finer nodalization scheme: hydrogen volumetric fraction within the break zone (4) and under the containment dome (21). 
of the steam generator boxes (control zone 1 in the old nodalization scheme). The results of simulations, including operation of the PARs system, are presented in Fig. 12 for the break zone and for the containment dome area (node 21).

The results are as expected: the same mass of hydrogen enters the smaller volume in this case, thus higher hydrogen concentration builds up much faster (compare with Fig. 8). Moreover, there were 24 PARs located within the break zone in the previous simulation, while there were only 6 in the second approach. Hydrogen concentration within the largest volume (the dome) rises a little bit slower, as this volume is not directly connected to the break zone.

\section{Final remarks and conclusions}

The lumped parameter approach allows for realization of multi-variant simulations in relatively short time. The results indicate the possibility of significant decrease in amount of hydrogen by means of passive catalytic recombiners. An important issue seems to be taking into account the influence of some parameters on the recombination rate. The hydrogen fraction at the inlet has been considered in this work, but this problem definitely needs further investigations.

A very important issue while using the lumped parameter approach is nodalization of the objects under consideration. As can be seen according to the analyzed case, the division on control zones affects the results significantly. Thus, the nodalization should be verified, by using experimental data or real nuclear power plant information, for example, by simulations of steady state operation.

When evaluating these results, it should be clearly noted that the analyses have been accomplished with a lumped parameter code. Such a code applies the perfect mixing condition within a control volume. Therefore, the results of simulations may be burdened with large uncertainties. It is obvious that, near the break location, the hydrogen concentration will cross the flammability limits much earlier than it is predicted by the code.

Crossing the flammability limits does not mean automatic hydrogen self-ignition - when there is a large amounts of steam, it prevents the combustion of hydrogen. On the other hand, a rapid condensation of steam may lead locally to high concentrations of hydrogen and may create detonable mixtures [13]. In order to obtain knowledge of local distribution of hydrogen, a more detailed modeling than lumped parameter approach is necessary.

There is another problem considering the hydrogen risk also: hydrogen combustion may be caused by an electric spark or when the gas stream hits some hot surface. These are some stochastic events and it is impossible to take them into account with satisfying accuracy.

In summary, it can be noted that the lumped parameter approach for modeling of thermal-hydraulic containment may lead to large uncertainties in some cases. Evaluating these uncertainties is very difficult.

Acknowledgments. Financial support under research task no. 7 "Study of hydrogen generation processes in nuclear reactors under regular operation conditions and in emergency cases, with suggested actions aimed at upgrade of nuclear safety" financed by the National Research and Development Centre in the framework of the strategic research project entitled "Technologies supporting development of safe nuclear power engineering" is greatly acknowledged. This study was conducted in Gliwice, Poland.

\section{References}

1. Sehgal, B. R. (Ed.) (2012). Nuclear safety in light water reactors. Severe accident phenomenology. Elsevier.

2. Bury, T. (2005). Analysis of thermal and flow processes within containments of water nuclear reactors during loss-of-coolant accidents. $\mathrm{PhD}$ thesis, Institute of Thermal Technology, Silesian University of Technology, Gliwice.

3. Fic, A., \& Skorek, J. (1993). Mathematical model of transient thermal and flow processes in containment of a PWR nuclear reactor. Archiwum Energetyki, $1 / 2,19-32$.

4. Orszulik, M., Fic, A., Bury, T., \& Składzień, J. (2013). A model of hydrogen passive autocatalytic recombiner and its validation via CFD simulations. Arch. Thermodyn., 34(4), 257-266.

5. Bury, T. (2002). Influence of the accident localization system construction on the course of the primary circuit rupture accident in VVER 440 units. Zeszyty Naukowe Politechniki Warszawskiej, seria Konferencje, 22(1), 169-176 (in Polish).

6. Techy, Z., Lajtha, G., \& Taubner, R. (1995). Accident loads for VVER-440/213 containment. Nucl. Eng. Des., 157, 375-385.

7. AREVA. (2011). AREVA passive autocatalytic recombiner. Paris: AREVA. (Document G-008-V1PB2011-ENG).

8. International Atomic Energy Agency. (2004). Status of advanced light water reactor designs. IAEA-TECDOC No. 1391. Vienna: IAEA.

9. Debontride, B. (2006). Design of EPR. In Proceedings on International Conference on Nuclear Power Plants for Poland, 1-2 June 2006 (pp. 10.1-10.11). Warsaw, Poland

10. AREVA. (2009). Applicability of AREVA NP containment response evaluation methodology to the U.S. $E P R^{\mathrm{TM}}$ for large break LOCA analysis. AREVA NP Inc. (Technical Report No. 10299-NP, Revision 1).

11. Kostka, P., Techy, Z., \& Sienicki, J. (2002). Hydrogen mixing analyses for a VVER containment. In Proceedings of 10th International Conference on Nuclear Engineering, 14-18 April 2002 (paper ICONE10-22206). Arlington, Virginia, USA.

12. AREVA. (2006). U.S. EPR severe accident evaluation topical report. AREVA NP Inc. (ANP-10268NP, Revision 0).

13. OECD/NEA. (1999). State-of-the-art report on containment thermalhydraulics and hydrogen distribution. Paris: CSNI. 